\title{
Molecular and Biochemical Characterization of Laboratory and Field Mutants of Botrytis cinerea Resistant to Fludioxonil
}

Weichao Ren, Wenyong Shao, Xu Han, Mingguo Zhou, and Changjun Chen, Key Laboratory of Monitoring and Management of Crop Diseases and Pest Insects, Ministry of Education, College of Plant Protection, Nanjing Agricultural University, Nanjing 210095, China

\begin{abstract}
Ren, W., Shao, W., Han, X., and Chen, C. 2016. Molecular and biochemical characterization of laboratory and field mutants of Botrytis cinerea resistant to fludioxonil. Plant Dis. 100:1414-1423.

Botrytis cinerea is a filamentous phytopathogen with a high risk of developing resistance to fungicides. The phenylpyrrole fungicide fludioxonil has been reported to have excellent activity against $B$. cinerea and increasingly has been applied to control gray mold in China. In this study, molecular and biochemical characteristics of laboratory and field mutants of $B$. cinerea resistant to fludioxonil has been investigated. During 2012 to 2014, $B$. cinerea isolates collected from Jiangsu and Shandong Provinces in China were tested in vitro for sensitivity to fungicides commonly used to suppress gray mold of cucumber and tomato. Among the 75 isolates collected from cucumber in 2013, two were highly resistant (HR) to fludioxonil. Of the 308 isolates collected from tomato in 2014, four were fludioxonil-HR. This was the first time that $B$. cinerea isolates HR to fludioxonil had been detected in the field. Six fludioxonil-resistant mutants were obtained in the laboratory by selection on fungicide-amended media.

These mutants exhibited stable resistance to fludioxonil, as indicated by resistance factor values that ranged from 34.38 to $>10,000$. In comparison with fludioxonil-sensitive isolates of $B$. cinerea, all field and laboratory mutants showed reduced fitness, as defined by mycelial growth, sporulation, virulence, and sensitivity to osmotic stress. When treated with fludioxonil at $1 \mu \mathrm{g} / \mathrm{ml}$, sensitive isolates showed increased glycerol contents in mycelium and expression levels of Bchog1, while levels in field and laboratory HR mutants increased only slightly. Sequences of the Bosl gene of field and laboratory fludioxonil-HR mutants showed that mutations in field mutants were located in the histidine kinase, adenylyl cyclase, methyl-accepting chemotaxis protein, and phosphatase (HAMP) domains of the $\mathrm{N}$-terminal region, whereas mutations in the laboratory mutants were distributed in HAMP domains or in the HATPase_c domain of the C-terminal region. These results will enhance our understanding of the resistance mechanism of $B$. cinerea to fludioxonil.
\end{abstract}

Gray mold, caused by necrotrophic fungus Botrytis cinerea (teleomorph Botryotinia fuckeliana), is a serious disease affecting a large number of economically important crops, including vegetables, fruit, and ornamental plants (Elad 1997; Williamson et al. 2007). Application of fungicides is one of the major approaches for management of this disease (Leroux 2007). However, Botrytis cinerea is considered at high risk to develop resistance to fungicides because of its high genetic variability, short life cycle, and prolific reproductive capacity (Leroux et al. 2002). The spread of B. cinerea populations resistant to multiple fungicides with different modes of action (e.g., benzimidazoles, carbamates, dicarboximides, anilinepyrimidines, and hydroxyanilide fungicides) has greatly reduced the usefulness of these compounds worldwide (Elad et al. 1992; Leroux et al. 2002; Myresiotis et al. 2007; Williamson et al. 2007).

Fludioxonil, a phenylpyrrole fungicide, is an analog of pyrrolnitrin, an antifungal antibiotic produced by Pseudomonas spp. (Nishida et al. 1965), and has a broad spectrum of activity (Raaijmakers et al. 2002). Previous studies have demonstrated that fludioxonil strongly interferes with mycelial growth and conidial germination of $B$. cinerea (Leroux 1996; Zhao et al. 2010). Since the mid-1990s, fludioxonil has been registered for commercial use to control a broad spectrum of fungi that infect seed, foliage, harvested fruit, and vegetables (Gehmann et al. 1990). Although their mode of action is not fully understood, phenylpyrroles are believed to target the osmotic-regulatory signal transduction pathway (Furukawa et al. 2012).

Two-component regulatory systems serve as a primary stimulusresponse cascade mechanism to allow organisms to sense and respond to changes in environmental conditions (Stock et al. 2000). They typically contain a membrane-bound histidine kinase (HK) that

Corresponding author: Changjun Chen; E-mail: changjun-chen@njau.edu.cn Accepted for publication 6 January 2016.

http://dx.doi.org/10.1094/PDIS-11-15-1290-RE

(C) 2016 The American Phytopathological Society senses a specific environmental stimulus and a corresponding response regulator that mediates the cellular response, mostly through differential expression of target genes (Mascher et al. 2006). Most fungi possess group III HK which carry a unique $\mathrm{N}$-terminal region, including HK, adenylyl cyclase, methyl-accepting chemotaxis protein, and phosphatase (HAMP) domain repeats (Yoshimi et al. 2005). It is clear that the fungal two-component systems are connected to a highosmolarity glycerol (HOG) mitogen-activated protein kinase (MAPK) pathway and that the group III HK appear to be positive regulators of the HOG1-type MAPK (Bahn 2008; Hohmann 2002; Meena et al. 2010). A previous study in salt-tolerant yeast Debaryomyces hansenii showed that interactions among the HAMP domains act as an "on-off" osmosensing switch (Ochiai et al. 2002). The group III HK also is a target for several fungicides such as dicarboximide and phenylpyrrole (Bahn et al. 2006; Hagiwara et al. 2007; Motoyama et al. 2005; Zhang et al. 2002). Fludioxonil causes improper activation of the HOG1-type MAPK which leads to cell death. Furthermore, a mutation in the group III HK can cause resistance to fludioxonil (Furukawa et al. 2007; Kojima et al. 2004). Both deletion and missense mutation of the group III HK display the same phenotypes; namely, fludioxonil resistance and hyperosmotic sensitivity (Ochiai et al. 2001; Yoshimi et al. 2004).

Laboratory mutants resistant to fludioxonil have been reported for B. cinerea and other fungal species ( $\mathrm{Li}$ and Xiao 2008; Ochiai et al 2001; Ziogas and Kalamarakis 2001). For the laboratory resistant mutants, mutations within the HAMP domains in the N-terminal region of group III HK OS-1 confer a high level of fludioxonil resistance (Duan et al. 2014; Fillinger et al. 2012; Vignutelli et al. 2002). Recently, B. cinerea strains with low resistance (LR) or moderately resistant (MR) to fludioxonil were reported in the field; however, mutations in the group III HK OS-1 were not detected in these fludioxonil-LR or -MR strains (Fernández-Ortuño et al. 2014a,b; Leroch et al. 2011; Li et al. 2014). To date, highly resistant (HR) mutants have not been reported from the field isolates.

The objectives of this study were to (i) determine whether fludioxonil-HR mutants were present in $B$. cinerea isolates collected from various hosts in different regions with a history of fludioxonil application, (ii) compare biological fitness parameters among 
fludioxonil-HR mutants of $B$. cinerea from field and laboratory, and (iii) analyze molecular and biochemical characteristics of the fludioxonil-HR mutants.

\section{Materials and Methods}

Fungal strains, fungicides, and culture media. $B$. cinerea isolates were isolated from symptomatic strawberry, tomato, and cucumber fruit and celery leaves in the field. Disease samples were collected from different geographical regions which were separated from each other by more than $10 \mathrm{~km}$ in Jiangsu and Shandong Province of China during 2012 to 2014. In these commercial fields, the main fungicides used to control gray mold were several fungicides in mixtures, including the anilinopyrimidine fungicide pyrimethanil and cyprodinil, the dicarboximide fungicide iprodione, and the fludioxonil-containing fungicide Celest, and had been used to control gray mold since 2012 . To obtain $B$. cinerea isolates, small tissue fragments cut from lesion margins were disinfected in $1 \% \mathrm{NaClO}$ for $3 \mathrm{~min}$, washed three times with sterile water, and placed on potato dextrose agar (PDA) plates amended with streptomycin sulfate (Solarbio Science \& Technology Co., Ltd.) at $100 \mu \mathrm{g} / \mathrm{ml}$. After 3 days at $25^{\circ} \mathrm{C}$, colony margins were transferred to fresh PDA plates, and pure cultures were then grown on PDA and inoculated at $25^{\circ} \mathrm{C}$ under a photoperiod of $12 \mathrm{~h}$ of light and $12 \mathrm{~h}$ of darkness facilitate sporulation. B. cinerea isolates were then single-spore cultured and mycelium plugs were maintained on PDA slants at $4{ }^{\circ} \mathrm{C}$. In total, 902 single-spore isolates of $B$. cinerea were obtained from these commercial fields (Table 1).

PDA was prepared with $200 \mathrm{~g}$ of potato, $20 \mathrm{~g}$ of dextrose, and $20 \mathrm{~g}$ of agar per liter of distilled water. Potato dextrose broth (PDB) had the same composition as PDA but without agar.

All fungicides used in sensitivity assays were of pure technical grade. Fludioxonil (provided by Yangzhou Younuo Chemicals Co., Ltd.; $97.9 \%$ active ingredient) was dissolved in methanol to obtain stock solutions of $5 \times 10^{4} \mu \mathrm{g} / \mathrm{ml}$.

Determination of sensitivity of $B$. cinerea to fludioxonil. To determine sensitivity of $B$. cinerea isolates to fludioxonil, a 5-mm mycelial plug was taken from the edge of a 3-day-old colony and placed on the center of PDA plates amended with fludioxonil. The discriminatory concentrations used for fludioxonil-sensitive (S), -LR, and -HR phenotypes were $0.1,1$, and $5 \mu \mathrm{g} / \mathrm{ml}$, respectively (Nishida et al. 1965). For each discriminatory concentration, complete cessation of growth was used as the criterion for classification of the categories of fludioxonil sensitivity. For example, an isolate was considered to be fludioxonil-S if it was not able to grow at $0.1 \mu \mathrm{g} / \mathrm{ml}$, and so on. The frequency of resistance to fludioxonil was calculated using the following formula: resistance frequency $=$ (number of resistant isolates/number of total isolates) $\times 100 \%$. The experiment was repeated three times, with four replicate plates per concentration for each isolate.

Induction of fludioxonil-resistant mutants of $B$. cinerea in vitro. To obtain laboratory-derived resistant mutants, sensitive strains $\mathrm{Nj1} 1-2$, Nj3-2, Nj4-6, Nj5-10, Bt2-4, Bt3-4, Bt6-4, 122 Bt10-3, Yc-2, and Yc-6 were selected randomly from the isolate collection. Fresh mycelial plugs (5 $\mathrm{mm}$ in diameter) from 3-day-old colony margins were transferred to PDA plates (six plugs per plate) amended with fludioxonil at $0.1 \mu \mathrm{g} / \mathrm{ml}$ (minimum inhibitory concentration [MIC]). After 15 to 20 days at $25^{\circ} \mathrm{C}$ in the dark, fast-growing mycelial tips were selected and transferred to new PDA plates amended with fludioxonil at $5.0 \mu \mathrm{g} / \mathrm{ml}$. Those that could grew on these plates were then placed on PDA containing fludioxonil at $50 \mu \mathrm{g} / \mathrm{ml}$ and, after 1 month at $25^{\circ} \mathrm{C}$ in the dark, fast-growing sectors were transferred to new PDA plates amended with the same fludioxonil concentration. This step was repeated until there was no significant difference in the linear growth of fast-growing sectors on the PDA plates with or without fludioxonil at $50 \mu \mathrm{g} / \mathrm{ml}$. This selection procedure was performed three times.

Characterization of laboratory and field resistant mutants of B. cinerea. Mycelial plugs from resistant mutants were placed on the center of PDA plates amended with fludioxonil at $0,0.3906$, $1.5625,6.25,25$, and $100 \mu \mathrm{g} / \mathrm{ml}$. Mycelial plugs from sensitive isolates were placed on fludioxonil-amended PDA plates at $0,0.003125$, $0.00625,0.0125,0.025$, and $0.05 \mu \mathrm{g} / \mathrm{ml}$. There were four replicate plates per concentration for each isolate. After incubation for 3 days in darkness at $25^{\circ} \mathrm{C}$, colony diameter (subtracting $5 \mathrm{~mm}$ for the mycelial plug) was measured at two points, with the second measurement perpendicular to the first. Percent inhibition (relative to the growth on plates without fludioxonil) was calculated and the effective concentration for $50 \%$ inhibition $\left(\mathrm{EC}_{50}\right)$ values were estimated from the regression of the probit (percent inhibition) log (fludioxonil concentration). A resistance factor (RF) was calculated for each isolate, which was defined as the $\mathrm{EC}_{50}$ of the resistant isolate divided by the $\mathrm{EC}_{50}$ of the sensitive parental strain.

For evaluating the resistance stability of $B$. cinerea to fludioxonil, all the resistant mutants were subject to 10 successive transfers on fungicide-free PDA. After the 10th transfer, RF was again determined. The resistance stability was denoted by the factor of sensitivity change (FSC) value: FSC $=\mathrm{RF}$ value of mutant at the $1 \mathrm{st}$ transfer/RF value of mutant at 10th transfer.

Determination of mycelial growth and spore production. Mycelial growth and spore production of sensitive and resistant isolates were compared on fungicide-free PDA. Cultures from mycelial plugs $\left(5 \mathrm{~mm}\right.$ in diameter) were grown for 14 days at $25^{\circ} \mathrm{C}$ with $12 \mathrm{~h}$ of light and $12 \mathrm{~h}$ of darkness. Mean colony diameter (subtracting the diameter of mycelial plug) was measured after 3 days. After 14 days, spores were collected from plates as previously described (Vignutelli et al. 2002). After the spore suspension was centrifuged at 5,000 rpm for $1 \mathrm{~min}$, the spore pellets were resuspended in $1 \mathrm{ml}$ of water and the concentration of the conidial suspension was determined by microscopic observation $(\times 400)$ with a hemacytometer. There were six replicate plates for each strain or mutant, and the experiment was repeated three times.

Virulence assay. Ability of sensitive and resistant isolates to cause infection on strawberry and tomato fruit was determined. Strawberry plants were grown in pots containing autoclaved potting mix and placed in a greenhouse $\left(20\right.$ to $28^{\circ} \mathrm{C}, 75$ to $90 \%$ relative humidity $[\mathrm{RH}]$, with supplemental light). Near the time of the first flowering

Table 1. Origin and sensitivity to fludioxonil of Botrytis cinerea isolates from different geographical regions in Jiangsu and Shandong Provinces of China during 2012 to $2014^{x}$

\begin{tabular}{|c|c|c|c|c|c|c|c|c|c|}
\hline \multirow[b]{2}{*}{ Location $^{y}$} & \multirow[b]{2}{*}{ Year } & \multirow[b]{2}{*}{ Host } & \multirow[b]{2}{*}{ Total $^{\mathbf{z}}$} & \multirow[b]{2}{*}{ Code } & \multicolumn{3}{|c|}{ Number of isolates } & \multicolumn{2}{|c|}{ Frequency (\%) } \\
\hline & & & & & $\mathbf{S}$ & LR & $\overline{H R}$ & LR & HR \\
\hline Nanjing, JS & 2012 & Strawberry & 62 & Nj1-X-Nj6-X & 62 & 0 & 0 & 0 & 0 \\
\hline Baitu, JS & 2012 & Strawberry & 228 & Bt1-X-Bt22-X & 228 & 0 & 0 & 0 & 0 \\
\hline Nanjing, JS & 2013 & Strawberry & 213 & Nj7-X-Nj29-X & 213 & 0 & 0 & 0 & 0 \\
\hline Yancheng, JS & 2013 & Celery & 16 & Yc-1-Yc-16 & 16 & 0 & 0 & 0 & 0 \\
\hline Shouguang, SD & 2013 & Cucumber & 75 & Sg-1-Sg-75 & 64 & 9 & 2 & 10.67 & 2.67 \\
\hline Weifang, SD & 2014 & Tomato & 308 & Wf-1-Wf-308 & 222 & 53 & 4 & 17.21 & 1.30 \\
\hline
\end{tabular}

${ }^{x}$ Frequency $=$ frequency of resistant isolates. $\mathrm{S}=$ sensitive, $\mathrm{LR}=$ with low resistance, and HR = highly resistant, with resistance defined by fludioxonil concentration in micrograms per milliliter.

y City and province (JS = Jiangsu Province and SD = Shandong Province) in China where isolates were collected.

$\mathrm{z}$ Total number of isolates. 
stage, mycelial plugs (5 $\mathrm{mm}$ in diameter) of each isolate were placed on the adaxial side of the strawberry leaves that had previously been wounded (avoiding major veins) with a sterilized needle. Leaf growing position and leaf size were similar for all treatments. After 5 days with $85 \% \mathrm{RH}$, the lesion diameter on each inoculated leaf was measured at two points, with the second measurement perpendicular to the first. Ten leaves for each isolate were used, and the experiment was performed three times.

On tomato fruit, virulence of sensitive and resistant isolates was assessed similarly. Mycelial plugs were placed on the surface of the tomato fruit over an artificial wound that facilitated the penetration of the fungus into the plant tissue. The inoculated fruit were placed on moistened filter paper and incubated in a growth chamber at $25^{\circ} \mathrm{C}$ with a 12 -h photoperiod and $85 \%$ RH. After 5 days, the lesion diameter was measured. Six replicate fruit were inoculated for each strain and the experiment was conducted three times.

Osmotic stress assay. For each isolate, mycelial plugs $(5 \mathrm{~mm}$ in diameter) were taken from the edge of a 3-day-old colony and transferred onto PDA containing $0.5 \mathrm{M} \mathrm{NaCl}, 0.5 \mathrm{M} \mathrm{KCl}, 0.8 \mathrm{M}$ glucose, $0.5 \mathrm{M}$ sorbitol, $0.2 \mathrm{M} \mathrm{CaCl}_{2}$, or $0.3 \mathrm{M} \mathrm{MgCl}_{2}$. PDA without osmoticum represented the control. Four replicate plates of each strain or mutant were incubated for 3 days at $25^{\circ} \mathrm{C}$. The percentage of inhibition of mycelial radial growth (relative to the growth on untreated control plates) was calculated. The experiment was repeated three times.

Determination of intracellular glycerol accumulation. Glycerol accumulation in the mycelia of each strain or mutant was determined using a commercial assay kit (Applygen Technologies Inc.), according to the manufacturer's instructions. Briefly, each strain or mutant was grown in PDB for 3 days at $25^{\circ} \mathrm{C}$ in a shaker. After treatment with fludioxonil at $1 \mu \mathrm{g} / \mathrm{ml}$ for $4 \mathrm{~h}$, the mycelia of each strain or mutant were harvested and ground in liquid nitrogen. Then, the mycelial powders $(0.1 \mathrm{~g})$ were transferred to a $2-\mathrm{ml}$ microcentrifuge tube containing $1 \mathrm{ml}$ of glycerol extraction buffer (Applygen Technologies). After vortexing for $5 \mathrm{~min}$, the tubes were centrifuged at $5,000 \times g$ for $20 \mathrm{~min}$. The resulting supernatant was used to determine the glycerol content of mycelia (Duan et al. 2013). The experiment was performed three times with four replicates.
Cloning and sequence analysis of Bos1. Genomic DNA was extracted from frozen mycelia by a cetyltrimethylammonium bromide method according to previous studies (Ristaino et al. 1998). Based on the sequence of the Bosl gene deposited in the Broad Institute $B$. cinerea Genome Database (Gene ID: BC1G_00374), the primer pairs Bos 1-F (5'-TACCGATCGAAAAACCCAAC-3') and Bos1-R (5'-AAGTACTCGCAGTCGGTGGT-3') were designed to amplify the complete Bos 1 gene from the strains or mutants analyzed. Polymerase chain reaction (PCR) amplifications were performed in a $25-\mu l$ volume containing $50 \mathrm{ng}$ of genomic DNA, $1 \mu \mathrm{l}$ of each primer (10 mM), $4 \mu \mathrm{l}$ of dNTP mixture ( $2.5 \mathrm{mM}$ of each dNTP), $2.5 \mu \mathrm{l}$ of $10 \times$ LA polymerase buffer $\left(\mathrm{Mg}^{2+}\right.$ free $), 2.5 \mu l$ of $\mathrm{MgCl}_{2}(25 \mathrm{mM})$, and $0.25 \mu \mathrm{l}$ of TaKaRa high-fidelity LA polymerase $(5 \mathrm{U} / \mu \mathrm{l})$ (TaKaRa Biotechnology Co., Ltd.). The following PCR parameters were used: an initial preheating for $5 \mathrm{~min}$ at $94^{\circ} \mathrm{C}$; followed by 35 cycles of denaturation at $94^{\circ} \mathrm{C}$ for $30 \mathrm{~s}$, annealing at $60^{\circ} \mathrm{C}$ for $30 \mathrm{~s}$, and extension at $72{ }^{\circ} \mathrm{C}$ for $4.5 \mathrm{~min}$; and a final extension at $72^{\circ} \mathrm{C}$ for $10 \mathrm{~min}$. PCR products amplified by the primer pairs contained 4,616 bp. PCR amplifications were performed three times independently for each strain or mutant to avoid sequence mismatch during PCR amplification and sequencing. All amplified PCR products were purified with the AxyPrep PCR Cleanup Kit (Axygen, Inc.) and sequenced by the Sangon Biotech Co., Ltd. DNAMAN software (version 6.0; Lynnon Biosoft Bioinformatic Solutions) was used to compare the amino acid sequences of the resistant mutants with those of the sensitive strains.

Determination of the expression of Bchog1. Expression of Bchogl in the resistant and sensitive isolates was assayed using methods developed by Wang et al. (2015). Briefly, each strain or mutant was grown in PDB with six replicate flasks. After 3 days at $25^{\circ} \mathrm{C}$ in a shaker, three of the six flasks of each strain or mutant were treated with fludioxonil at $1 \mu \mathrm{g} / \mathrm{ml}$, and the other three flasks were used as controls. After $4 \mathrm{~h}$, the mycelia of each strain or mutant were harvested. Total RNA was extracted using TRIzol reagent (Invitrogen). The extract RNA was treated with DNase (TaKaRa Biotechnology Co., Ltd.) and used for cDNA synthesis with the PrimeScript RT reagent kit (TaKaRa Biotechnology Co., Ltd.). Primers used for quantitative real-time (qRT)-PCR were actin-QF/QR (5'-TGTCACCAACTGG

Table 2. Stability and level of fludioxonil resistance for the laboratory and field isolates of Botrytis cinerea

\begin{tabular}{|c|c|c|c|c|c|c|c|}
\hline \multirow[b]{2}{*}{ Isolates or mutants } & \multirow[b]{2}{*}{ Sensitivity ${ }^{x}$} & \multirow[b]{2}{*}{ Origin $^{y}$} & \multicolumn{2}{|c|}{$\mathrm{EC}_{50}(\mu \mathrm{g} / \mathrm{ml})^{\mathrm{v}}$} & \multicolumn{2}{|c|}{$\mathbf{R F}^{\mathbf{w}}$} & \multirow[b]{2}{*}{ FSC $^{\mathbf{z}}$} \\
\hline & & & 1st & 10th & 1st & 10th & \\
\hline $\mathrm{Nj} 5-10$ & $\mathrm{~S}$ & Field isolate & 0.0056 & 0.0069 & $\ldots$ & $\ldots$ & $\ldots$ \\
\hline Bt3-4 & $\mathrm{S}$ & Field isolate & 0.0086 & 0.0084 & $\ldots$ & $\ldots$ & $\ldots$ \\
\hline Bt6-4 & S & Field isolate & 0.0073 & 0.0078 & $\ldots$ & $\ldots$ & $\ldots$ \\
\hline Yc-6 & $\mathrm{S}$ & Field isolate & 0.0075 & 0.0068 & $\ldots$ & $\ldots$ & $\ldots$ \\
\hline $\mathrm{Sg}-2$ & $\mathrm{~S}$ & Field isolate & 0.038 & 0.036 & $\ldots$ & $\ldots$ & $\ldots$ \\
\hline $\mathrm{Sg}-28$ & $\mathrm{~S}$ & Field isolate & 0.016 & 0.017 & $\ldots$ & $\ldots$ & $\ldots$ \\
\hline Wf-20 & $\mathrm{S}$ & Field isolate & 0.0091 & 0.011 & $\ldots$ & $\ldots$ & $\ldots$ \\
\hline Wf-142 & $\mathrm{S}$ & Field isolate & 0.013 & 0.013 & $\ldots$ & $\ldots$ & $\ldots$ \\
\hline Bt6-4R2 & LR & Laboratory mutant & 0.42 & 0.37 & 57.74 & 47.33 & 0.82 \\
\hline Yc-6R2 & LR & Laboratory mutant & 0.29 & 0.23 & 38.23 & 34.38 & 0.90 \\
\hline Nj5-10R & HR & Laboratory mutant & $>100$ & $>100$ & $>10,000$ & $>10,000$ & $\ldots$ \\
\hline Bt3-4R & HR & Laboratory mutant & 4.01 & 3.34 & 466.69 & 402.96 & 0.86 \\
\hline Bt6-4R1 & HR & Laboratory mutant & $>100$ & $>100$ & $>10,000$ & $>10,000$ & $\ldots$ \\
\hline Yc-6R1 & HR & Laboratory mutant & $>100$ & $>100$ & $>10,000$ & $>10,000$ & $\ldots$ \\
\hline Sg-17 & $\mathrm{HR}$ & Field mutant & $>100$ & $>100$ & $>3,000$ & $>3,000$ & $\ldots$ \\
\hline $\mathrm{Sg}-38$ & $\mathrm{HR}$ & Field mutant & $>100$ & $>100$ & $>3,000$ & $>3,000$ & $\ldots$ \\
\hline Wf-55 & HR & Field mutant & $>100$ & $>100$ & $>8,000$ & $>8,000$ & $\ldots$ \\
\hline Wf-161 & HR & Field mutant & $>100$ & $>100$ & $>8,000$ & $>8,000$ & $\ldots$ \\
\hline Wf-192 & HR & Field mutant & $>100$ & $>100$ & $>8,000$ & $>8,000$ & $\ldots$ \\
\hline Wf-202 & HR & Field mutant & $>100$ & $>100$ & $>8,000$ & $>8,000$ & $\ldots$ \\
\hline
\end{tabular}

$\mathrm{v} \mathrm{EC}_{50}=$ effective concentration for $50 \%$ inhibition of mycelial growth at the 1st transfer and the 10th transfer.

${ }^{\mathrm{w}} \mathrm{RF}=$ resistance factor, a ratio of $\mathrm{EC}_{50}$ for a fludioxonil-resistant mutant relative to the $\mathrm{EC}_{50}$ for the sensitive isolate.

x Sensitivity to fludioxonil: $\mathrm{S}=$ sensitive, $\mathrm{LR}=$ with low resistance, and $\mathrm{HR}=$ highly resistant, with resistance defined by fludioxonil concentration in micrograms per milliliter.

y Laboratory mutants were obtained by mass selection on fludioxonil-amended medium; field isolates were collected from the field locations.

${ }^{\mathrm{z}} \mathrm{FSC}=$ the ratio of RF values at the 1st and 10th transfer. 
GATGATATG-3' ${ }^{\prime} 5^{\prime}$-CTGTTGGACTTTGGGTTGATTG- $3^{\prime}$ ) for the reference gene actin (BC1G_08198.1) and hog1-QF/QR (5'CGGCACCACCTTTGAGATTA-3' $/ 5^{\prime}$-AACCGGTGAGGTTATC TTTGG-3') for Bchog1. qRT-PCR was performed in an ABI 7500 Real-Time Detection System (Applied Biosystems) using SYBR Green I fluorescent dye detection. Amplification was performed in a $20-\mu l$ volume containing $10 \mu \mathrm{l}$ of iTaq Universal SYBR Green Supermix (Bio-Rad Laboratories), $2 \mu 1$ of the reverse transcription product, and $1 \mu \mathrm{l}$ each of the forward and reverse primers $(500 \mathrm{nM}$ each). The expression of the measured genes in each sample was normalized to actin gene expression, and relative changes in gene expression levels were analyzed by ABI 7500 SDS software (Applied Biosystems), which automatically set the baseline. qRT-PCR data from three biological replicates were used to calculate the mean and standard deviation for the expression level of each gene. The experiment was performed three times.

Table 3. Sensitivity of fludioxonil-resistant mutants and fludioxonil-sensitive isolates of Botrytis cinerea to procymidone and iprodione

\begin{tabular}{|c|c|c|c|c|c|}
\hline \multirow[b]{2}{*}{ Isolates or mutants } & \multirow[b]{2}{*}{ Sensitivity ${ }^{y}$} & \multirow[b]{2}{*}{ Origin $^{z}$} & \multicolumn{3}{|c|}{$\mathrm{EC}_{50}(\mu \mathrm{g} / \mathrm{ml})^{\mathrm{x}}$} \\
\hline & & & Fludioxonil & Procymidone & Iprodione \\
\hline $\mathrm{Nj5}-10$ & $S$ & Field isolate & $0.0062 \mathrm{e}$ & $0.38 \mathrm{i}$ & $0.051 \mathrm{f}$ \\
\hline Bt3-4 & $\mathrm{S}$ & Field isolate & $0.0087 \mathrm{e}$ & $1.95 \mathrm{~h}$ & $2.59 \mathrm{cde}$ \\
\hline Bt6-4 & S & Field isolate & $0.0078 \mathrm{e}$ & $2.21 \mathrm{fg}$ & $2.92 \mathrm{~cd}$ \\
\hline Yc-6 & S & Field isolate & $0.0072 \mathrm{e}$ & $0.19 \mathrm{j}$ & $0.23 \mathrm{f}$ \\
\hline $\mathrm{Sg}-2$ & S & Field isolate & $0.35 \mathrm{de}$ & $2.11 \mathrm{~g}$ & $1.25 \mathrm{def}$ \\
\hline Sg-28 & $S$ & Field isolate & $>100 \mathrm{a}$ & $>100 a^{\circ}$ & $>100 \mathrm{a}$ \\
\hline Wf-20 & S & Field isolate & $0.016 \mathrm{e}$ & $3.93 \mathrm{c}$ & $1.21 \mathrm{ef}$ \\
\hline Wf-142 & $S$ & Field isolate & $0.013 \mathrm{e}$ & $3.81 \mathrm{~d}$ & $2.31 \mathrm{cde}$ \\
\hline Bt6-4R2 & LR & Laboratory mutant & $0.39 \mathrm{c}$ & $3.63 \mathrm{e}$ & $3.53 \mathrm{c}$ \\
\hline Yc-6R2 & LR & Laboratory mutant & $0.26 \mathrm{~d}$ & $15.57 \mathrm{~b}$ & $3.71 \mathrm{c}$ \\
\hline $\mathrm{Nj5}-10 \mathrm{R}$ & HR & Laboratory mutant & $>100 \mathrm{a}$ & $>100 \mathrm{a}$ & $>100 \mathrm{a}$ \\
\hline Bt3-4R & HR & Laboratory mutant & $3.74 \mathrm{~b}$ & $>100 \mathrm{a}$ & $>100 \mathrm{a}$ \\
\hline Bt6-4R1 & HR & Laboratory mutant & $>100 \mathrm{a}$ & $>100 \mathrm{a}$ & $>100 \mathrm{a}$ \\
\hline Yc-6R1 & HR & Laboratory mutant & $>100 \mathrm{a}$ & $>100 \mathrm{a}$ & $>100 \mathrm{a}$ \\
\hline Sg-17 & HR & Field mutant & $>100 \mathrm{a}$ & $>100 \mathrm{a}$ & $52.19 \mathrm{~b}$ \\
\hline $\mathrm{Sg}-38$ & HR & Field mutant & $>100 \mathrm{a}$ & $>100 \mathrm{a}$ & $>100 \mathrm{a}$ \\
\hline Wf-55 & HR & Field mutant & $>100 \mathrm{a}$ & $>100 \mathrm{a}$ & $>100 \mathrm{a}$ \\
\hline Wf-161 & HR & Field mutant & $>100 \mathrm{a}$ & $>100 \mathrm{a}$ & $>100 \mathrm{a}$ \\
\hline Wf-192 & $\mathrm{HR}$ & Field mutant & $>100 \mathrm{a}$ & $>100 \mathrm{a}$ & $>100 \mathrm{a}$ \\
\hline Wf-202 & HR & Field mutant & $>100 \mathrm{a}$ & $>100 \mathrm{a}$ & $>100 \mathrm{a}$ \\
\hline
\end{tabular}

${ }^{\mathrm{x}} \mathrm{EC}_{50}=$ effective concentration for $50 \%$ inhibition of mycelial growth; means in a column followed by the same letter are not different according to Fisher's least significant difference $(P=0.05)$.

y Sensitivity to fludioxonil: $\mathrm{S}=$ sensitive, $\mathrm{LR}=$ with low resistance, and $\mathrm{HR}=$ highly resistant, with resistance defined by fludioxonil concentration in micrograms per milliliter.

z Laboratory mutants were obtained by selection on fludioxonil-amended medium; field isolates were collected from the field locations.

Table 4. Comparison in mycelial growth, sporulation, and virulence of Botrytis cinerea resistant or sensitive to fludioxonil

\begin{tabular}{|c|c|c|c|c|c|}
\hline \multirow[b]{2}{*}{ Isolates or mutants } & \multirow[b]{2}{*}{ Origin $^{x}$} & \multirow[b]{2}{*}{ Growth $(\mathbf{c m})^{y}$} & \multirow[b]{2}{*}{ Sporulation $^{\mathrm{z}}$} & \multicolumn{2}{|c|}{ Virulence (lesion area, $\left.\mathrm{cm}^{2}\right)^{\mathrm{w}}$} \\
\hline & & & & Strawberry leaves & Tomato fruit \\
\hline Nj5-10 & Field, S & $6.12 \mathrm{~d}$ & $43.8 \mathrm{f}$ & $3.90 \mathrm{f}$ & $6.99 \mathrm{e}$ \\
\hline Bt3-4 & Field, S & $7.39 \mathrm{ab}$ & $100 \mathrm{a}$ & $14.41 \mathrm{a}$ & $14.79 \mathrm{a}$ \\
\hline Bt6-4 & Field, S & $6.22 \mathrm{~d}$ & $63.7 \mathrm{~d}$ & $7.30 \mathrm{~cd}$ & $8.64 \mathrm{~d}$ \\
\hline Yc-6 & Field, S & $7.9 \mathrm{ab}$ & $43.3 \mathrm{f}$ & 4.12 ef & $10.65 \mathrm{c}$ \\
\hline $\mathrm{Sg}-2$ & Field, S & $8.20 \mathrm{a}$ & $77.7 \mathrm{~b}$ & $6.61 \mathrm{~d}$ & $12.54 \mathrm{~b}$ \\
\hline $\mathrm{Sg}-28$ & Field, S & $7.5 \mathrm{ab}$ & $67.7 \mathrm{c}$ & $5.09 \mathrm{e}$ & $11.80 \mathrm{bc}$ \\
\hline Wf-20 & Field, S & $7.17 \mathrm{bc}$ & $57.9 \mathrm{e}$ & $7.72 \mathrm{bc}$ & $10.72 \mathrm{c}$ \\
\hline Wf-142 & Field, S & $7.73 \mathrm{ab}$ & $67.4 \mathrm{c}$ & $8.75 \mathrm{~b}$ & $13.14 \mathrm{~b}$ \\
\hline Bt6-4R2 & Laboratory, LR & $6.35 \mathrm{~cd}$ & $60.8 \mathrm{de}$ & $4.01 \mathrm{f}$ & $2.36 \mathrm{gh}$ \\
\hline Yc-6R2 & Laboratory, LR & $8.01 \mathrm{ab}$ & $0 \mathrm{j}$ & $0 \mathrm{i}$ & $0 \mathrm{j}$ \\
\hline $\mathrm{Nj5}-10 \mathrm{R}$ & Laboratory, HR & $5.53 \mathrm{def}$ & $0.1 \mathrm{j}$ & $0.08 \mathrm{i}$ & $0.5 \mathrm{ij}$ \\
\hline $\mathrm{Bt} 3-4 \mathrm{R}$ & Laboratory, HR & $4.26 \mathrm{~g}$ & $4.2 \mathrm{j}$ & $0.22 \mathrm{i}$ & $0.26 \mathrm{ij}$ \\
\hline Bt6-4R1 & Laboratory, HR & $5.68 \mathrm{de}$ & $7.9 \mathrm{~h}$ & $0.96 \mathrm{hi}$ & $0.21 \mathrm{ij}$ \\
\hline Yc-6R1 & Laboratory, HR & $6.38 \mathrm{~cd}$ & $0.2 \mathrm{j}$ & $2.15 \mathrm{~g}$ & $3.32 \mathrm{fg}$ \\
\hline Sg-17 & Field, HR & $5.53 \mathrm{def}$ & $0.5 \mathrm{j}$ & $0.63 \mathrm{hi}$ & $1.33 \mathrm{hij}$ \\
\hline Sg-38 & Field, HR & $4.53 \mathrm{~g}$ & $0.4 \mathrm{j}$ & $2.28 \mathrm{j}$ & $2.12 \mathrm{gh}$ \\
\hline Wf-55 & Field, HR & 4.87 efg & $20.2 \mathrm{~g}$ & $2.47 \mathrm{~g}$ & $3.94 \mathrm{f}$ \\
\hline Wf-161 & Field, HR & $4.67 \mathrm{fg}$ & $0.3 \mathrm{j}$ & $0.56 \mathrm{i}$ & $1.55 \mathrm{hi}$ \\
\hline Wf-192 & Field, HR & $4.40 \mathrm{~g}$ & $0.4 \mathrm{j}$ & $1.63 \mathrm{gh}$ & $1.73 \mathrm{hi}$ \\
\hline Wf-202 & Field, HR & $4.93 \mathrm{efg}$ & $2.9 \mathrm{ij}$ & $1.64 \mathrm{gh}$ & $1.02 \mathrm{hij}$ \\
\hline
\end{tabular}

v Means in a column followed by the same letter are not different according to Fisher's least significant difference $(P=0.05)$.

${ }^{w}$ Lesion areas were determined on strawberry leaves and tomato fruit.

${ }^{x}$ Field, $\mathrm{S}=$ field sensitive isolates; laboratory, $\mathrm{HR}$ or LR = highly resistant mutants or mutants with low resistance, respectively, which were obtained by selection on fludioxonil-amended medium in the laboratory; and field, $\mathrm{HR}=\mathrm{HR}$ mutants which were collected from the field locations.

${ }^{y}$ Mycelia growth was measured after inoculation at $25^{\circ} \mathrm{C}$ for 3 days on fungicide-free potato dextrose agar (PDA) plates.

${ }^{\mathrm{z}}$ Spores $\left(\times 10^{6}\right.$ spores/petri plate) produced on PDA medium 14 days after inoculation. 
Statistical analysis. Owing to homogeneity of variances between experiments, data from repeated experiments were combined for analysis. All data were processed with the SIGMA-STAT Statistical Software Package (SPSS Science, version 11). The $\mathrm{EC}_{50}$ was obtained by a linear regression of the probit of the percent inhibition relative to the control against the $\log _{10}$-transformed fungicide concentrations. $\mathrm{EC}_{50}$ values, colony diameters, sporulation, and lesion areas were assessed using a one-way analysis of variance and means were compared with Fisher's protected least significant difference $(P=0.05)$. Cross-resistance between fungicides was analyzed using Spearman's rank correlation coefficient for the log-transformed $\mathrm{EC}_{50}$ values. The biological fitness (e.g., mycelial growth, sporulation, and virulence) of the laboratory and field resistant mutants was compared using the $t$ test.

\section{Results}

Sensitivity of $\boldsymbol{B}$. cinerea to fludioxonil. Among the 503 strains of B. cinerea from infected strawberry in Nanjing and Baitu City, Jiangsu Province during 2012 to 2013 and the 16 strains from infected celery leaves in Yancheng City, Jiangsu Province in 2013, no fludioxonil-resistant mutants were detected (Table 1). Of the 75 strains from infected cucumber in Shouguang City, Shandong Province in 2014, 9 strains were LR to fludioxonil and 2 strains were HR to fludioxonil, with resistance frequencies of 10.67 and $2.67 \%$ for the
A

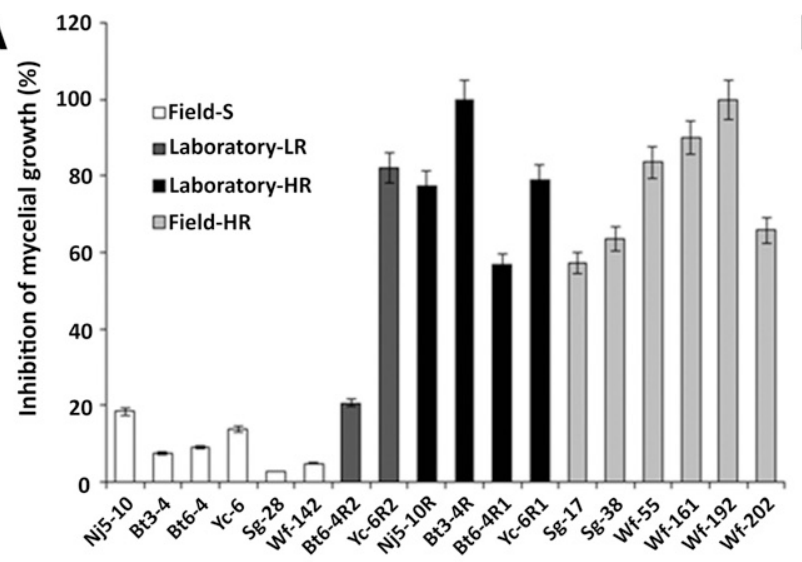

Treatment with $0.5 \mathrm{M} \mathrm{NaCl}$

C

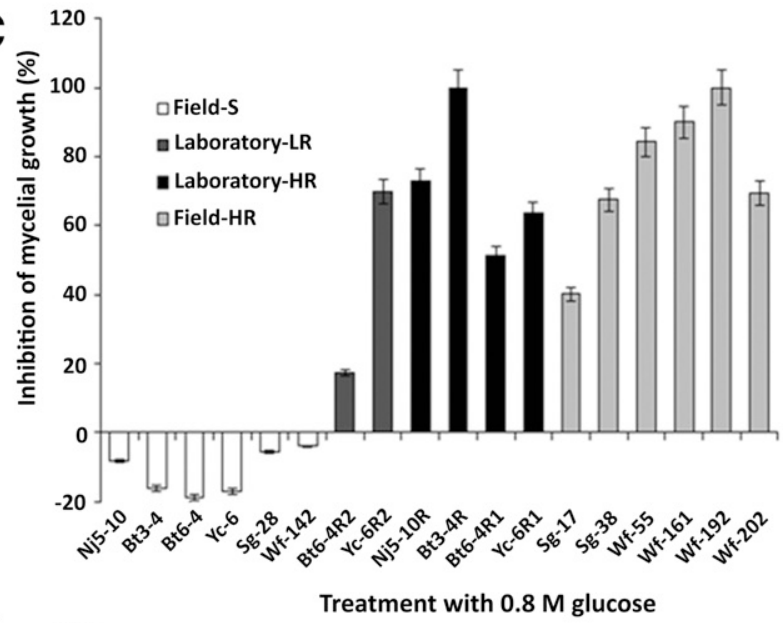

E

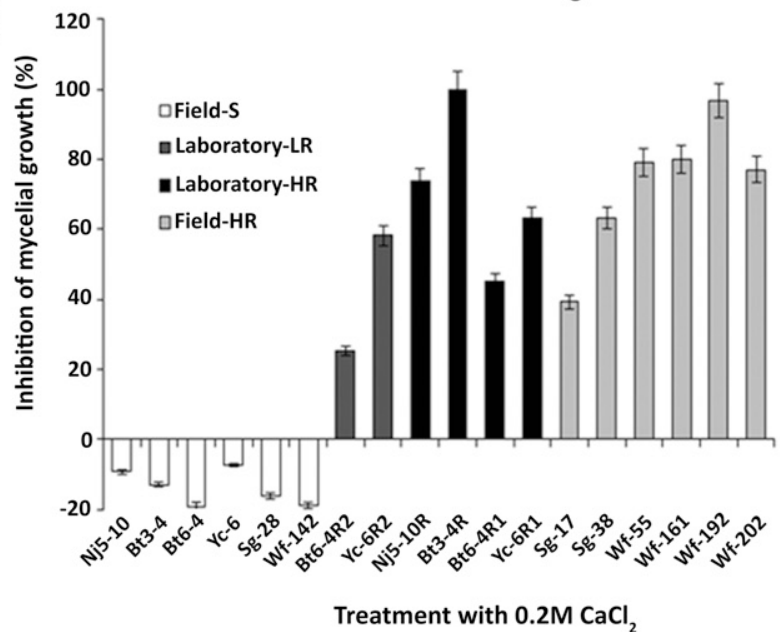

B

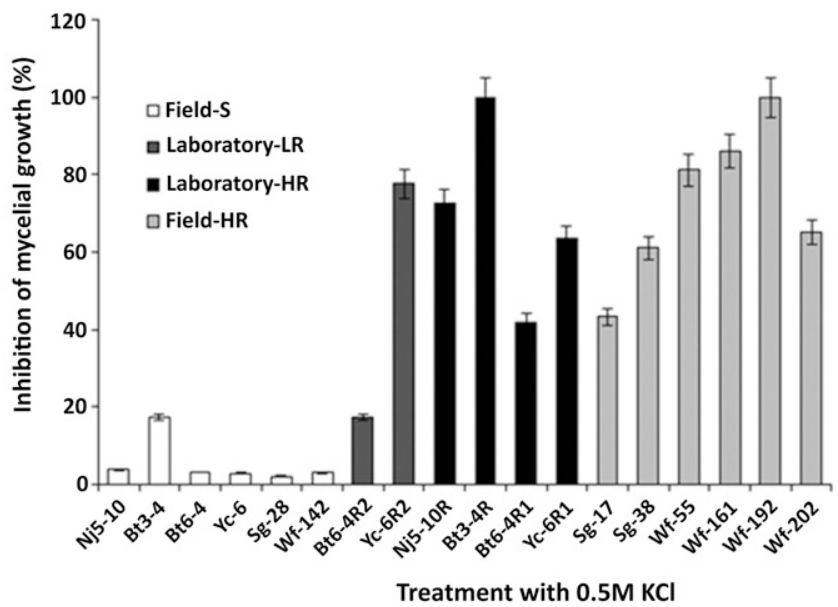

D

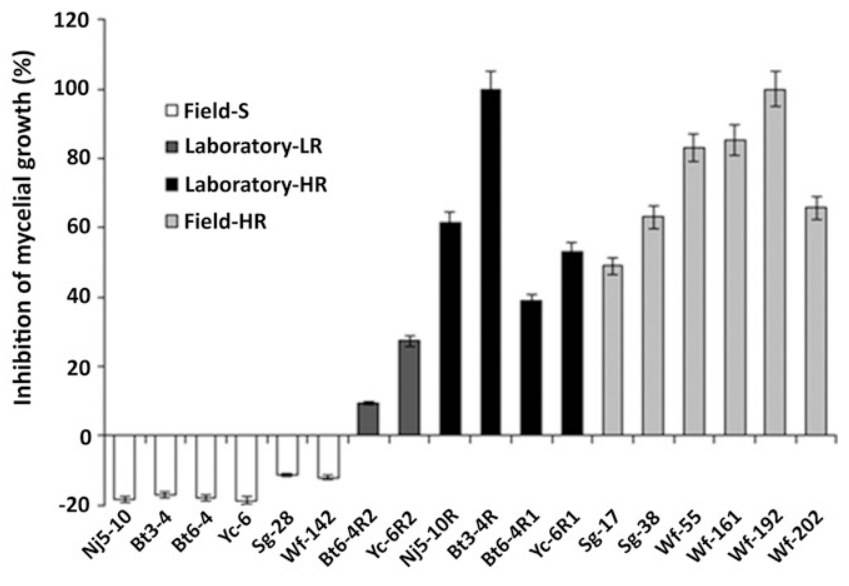

$\mathbf{F}$

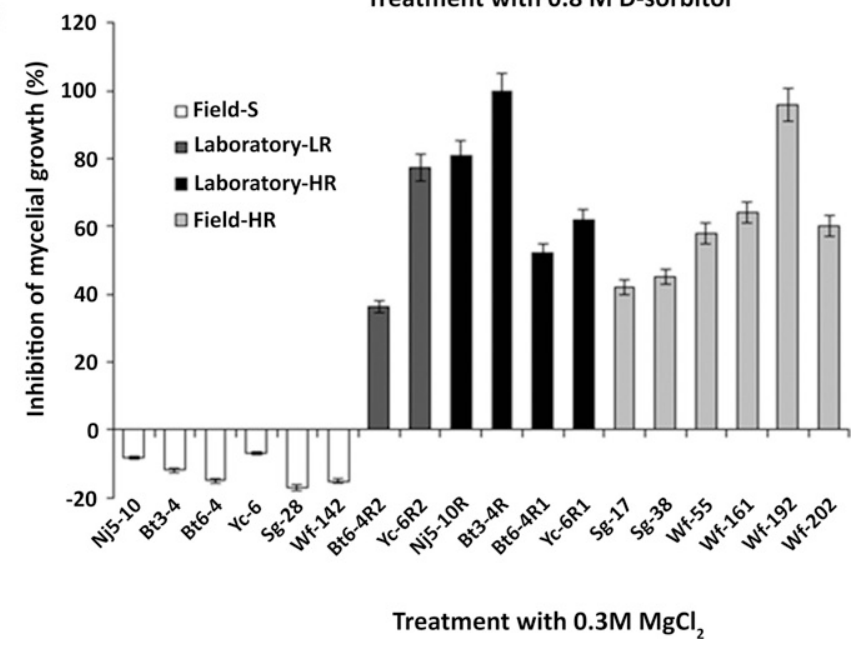

Fig. 1. Sensitivity of the laboratory and field fludioxonil-resistant mutants and sensitive isolates of Botrytis cinerea to osmotic stress generated by A, NaCl; $\mathbf{B}, \mathrm{KCl} ; \mathbf{C}$, glucose; D, D-sorbitol; $\mathrm{E}, \mathrm{CaCl}_{2}$; or $\mathrm{F}, \mathrm{MgCl}_{2}$. Bars denote the standard errors of three repeated experiments. 
LR and HR phenotypes, respectively (Table 1). Of the 308 strains from infected tomato in Weifang City, Shandong Province in 2014, 53 strains were LR to fludioxonil and 4 strains were HR to fludioxonil, which represented resistance frequencies of 17.21 and $1.30 \%$ for LR and HR phenotypes, respectively (Table 1). These six field HR strains from infected cucumber and tomato were used for further study.

Generation of $B$. cinerea mutants resistant to fludioxonil in vitro. From the 10 wild-type isolates exposed to fludioxonil at $0.1 \mu \mathrm{g} / \mathrm{ml}$ (MIC) in an in vitro assay, as a whole, the resistant mutants $\mathrm{Nj5}-10 \mathrm{R}$, Bt3-4R, Bt6-4R1, Bt6-4R2, Yc-6R1, and Yc-6R2 were obtained from the parental strains $\mathrm{Nj5-10,Bt3-4,} \mathrm{Bt6-4,} \mathrm{and} \mathrm{Yc-6.} \mathrm{Con-}$ sidering the $\mathrm{EC}_{50}$ values detailed in Table 2, the mutants were identified as HR (Nj5-10R, Bt3-4R, Bt6-4R1, and Yc-6R1; $4.01<$ $\mathrm{EC}_{50}>100 \mu \mathrm{g} / \mathrm{ml}$ ) or LR (Bt6-4R2 and Yc-6R2; $0.28651<\mathrm{EC}_{50}>$ $0.4215 \mu \mathrm{g} / \mathrm{ml})$. The isolates obtained from fields with an $\mathrm{EC}_{50}$ $>100 \mu \mathrm{g} / \mathrm{ml}$ were identified as HR.

Characterization of laboratory and field mutants of $B$. cinerea stability and level of fludioxonil resistance. After 10 transfers on fungicide-free PDA, all of the laboratory and field resistant mutants were stable and still could grow on PDA amended with fludioxonil at $50 \mu \mathrm{g} / \mathrm{ml}$, while the sensitive isolates could grow at $0.1 \mu \mathrm{g} / \mathrm{ml}$. For the six HR mutants detected from the field, $\mathrm{EC}_{50}$ values were
$>100 \mu \mathrm{g} / \mathrm{ml}$, with RF values $>1,000$. RF values for fludioxonilresistant isolates selected in the laboratory ranged from 34.38 to $>10,000$ (Table 2).

Cross-resistance. Based on $\mathrm{EC}_{50}$ values, all the laboratory and field isolates resistant to fludioxonil also were resistant to dicarboximide fungicides (procymidone and iprodione; Table 3). Spearman rank correlations for cross-resistance between fludioxonil and procymidone or iprodione were 0.9358 and 0.8992 , respectively $(P<0.00001)$. This showed that there was a strong positive correlation between the resistance of fludioxonil and dicarboximide fungicides (e.g., procymidone and iprodione) in $B$. cinerea.

Mycelial growth and sporulation of laboratory and field mutants. For the laboratory mutants, mycelial growth was significantly reduced on nonfungicide-amended media compared with their parental strains, except for mutant Yc-6R2 $(P=0.05)$ (Table 4). Except for Bt6-4R2, sporulation of resistant isolates from the laboratory decreased by approximately 87.6 to $100 \%$ when compared with sporulation of the parental strain (Table 4). Significant reductions in mycelia growth $(P=0.05$, approximately 29.6 to $43.0 \%$ reduction $)$ and sporulation ( $P=0.05$, approximately 68.2 to $99.4 \%$ reduction) also were observed in fludioxonil-resistant isolates from the field (Table 4). Based on a $t$ test, differenced in mycelia growth and

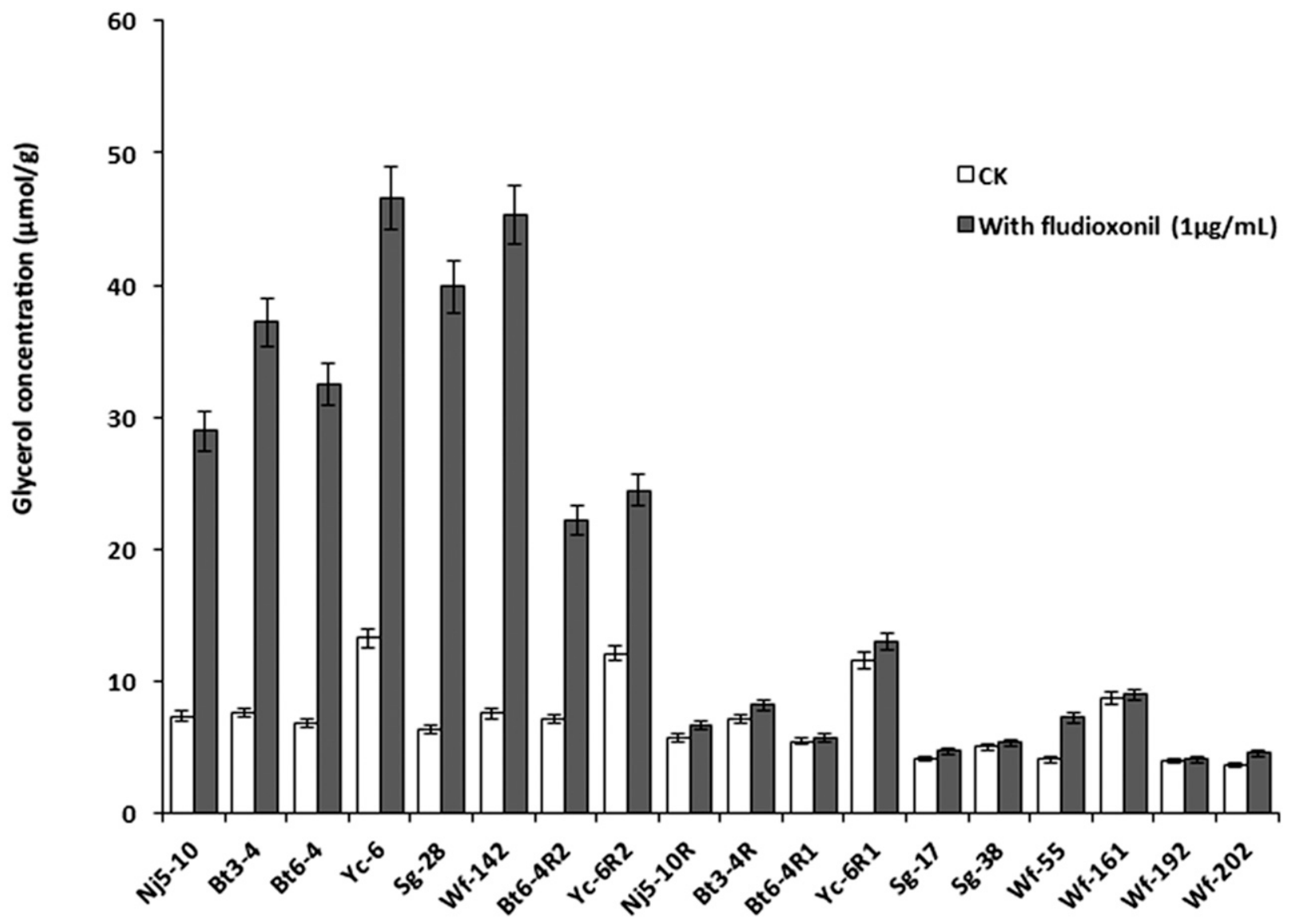

Fig. 2. Comparison in intracellular glycerol concentration of fludioxonil-resistant mutants and sensitive isolates of Botrytis cinerea. The mycelia of each isolate or mutant were treated with fludioxonil at $1 \mu \mathrm{g} / \mathrm{ml}$ after growth in potato dextrose broth for 3 days. Cultures without treatment were used as the controls (CK). Bars denote standard errors from three repeated experiments.

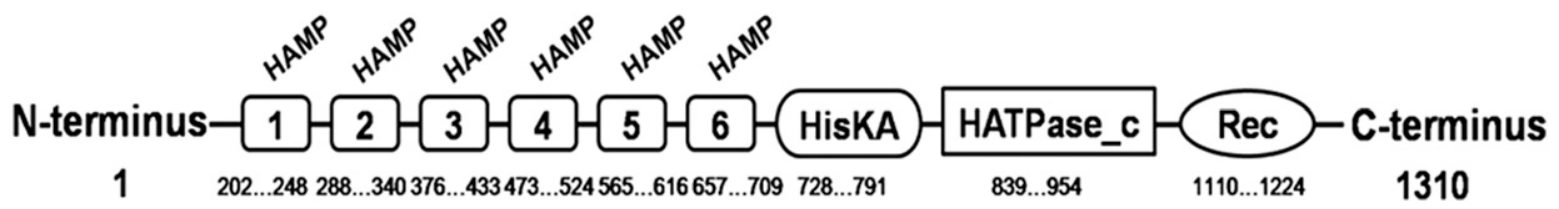

Fig. 3. Schematic representation of the domain architecture of Bos1, including histidine kinase, adenylyl cyclase, methyl-accepting chemotaxis protein, and phosphatase (HAMP) domain repeats; the His kinase A (phospho-acceptor) domain (HisKA); the HK-like ATPase domain (HATPase_c); and the response regulator domain (Rec). 
sporulation among groups of laboratory and field mutants were not significant $(P>0.05)$.

Virulence of laboratory and field resistant mutants on strawberry and tomato. Except for Yc-6R2, all the fludioxonil-resistant isolates from the laboratory and field were virulent on strawberry leaves and tomato fruit. However, the resistant isolates had significantly smaller lesions compared with sensitive strains $(P=0.05)$ (Table 4). There was no significant difference in lesion size on strawberry leaves or tomato fruit among the groups of laboratory and field isolates $(P>0.05)$.

Sensitivity to osmotic stress. Mycelial growth of the sensitive strains was slightly inhibited by $0.5 \mathrm{M} \mathrm{NaCl}$ and $0.5 \mathrm{M} \mathrm{KCl}$ while that of the fludioxonil-resistant isolates was strongly inhibited (Fig. $1 \mathrm{~A}$ and $\mathrm{B}$ ). Under treatment with $0.8 \mathrm{M}$ glucose, 0.5 M D-sorbitol, $0.2 \mathrm{M} \mathrm{CaCl}_{2}$, or $0.3 \mathrm{M} \mathrm{MgCl}_{2}$, mycelial growth of the sensitive strains was increased; however, the resistant mutants exhibited significantly $(P=0.05)$ reduced mycelial growth (Fig. 1C, D, E, and $F)$. These results indicated that both laboratory and field resistant mutants showed increased sensitivity to increased osmotic potential. The field mutants tested were more sensitive than laboratory mutants to D-sorbitol $(P<0.05)$ but there was no significant difference in sensitivity to $\mathrm{NaCl}, \mathrm{KCl}$, glucose, $\mathrm{CaCl}_{2}$, or $\mathrm{MgCl}_{2}$ between the groups of laboratory and field mutants $(P>0.05)$.

Intracellular glycerol accumulation. In the absence of fludioxonil, glycerol concentrations in the sensitive strains and resistant mutants were relatively low. When treated with fludioxonil at $1 \mu \mathrm{g} / \mathrm{ml}$, glycerol concentrations in the sensitive strains increased significantly but those in the resistant mutants (except for two laboratory LR mutants Bt6-4R2 and Yc-6R2) also increased significantly (Fig. 2). Although the two LR mutants exhibited increased glycerol accumulation, the glycerol concentrations were significantly lower than those in the sensitive strains treated with fludioxonil (Fig. 2).

Sequence variation in Bos 1 from laboratory and field mutants. Analysis of the predicted 1,310-amino-acid sequence of Bos 1 (BC1G_00374.1) with the InterProScan prediction server detected all the characteristic domains of Bos 1 , including six HAMP domain repeats, the His kinase A (phospho-acceptor) domain, the HK-like ATPase domain (HATPase_c), and the response regulator domain (Fig. 3). The complete Bos1 gene was cloned and sequenced from the resistant mutants and sensitive strains. The amino acid changes observed are listed in Table 5.

The sequences of Bos 1 were identical for all the sensitive strains tested. For the laboratory resistant mutants, four HR mutants had various mutations in Bos 1 and the two LR mutants, Bt6-4R2 and Yc-6R2, had no mutations. The mutants Bt3-4R and Yc-6R1 had single-point mutations E253D (an amino acid changed from glutamic to aspartic at position 253) and G415D (an amino acid changed from glycine to aspartic at position 415), respectively. The mutant $\mathrm{Nj5}$ 10R carried a mutation in the Bos 1 at codon 81 (Q846STOP), leading to precocious stop of translation. In the mutant Bt6-4R1, a duplication of a 55-bp sequence was found at amino acid position 835, causing a frameshift and resulting in a premature stop codon at amino acid position 838. For the field HR mutants, Wf-55, Wf-161, Wf-192, and Wf-202 had single-point mutations G311R (an amino acid changed from glycine to arginine at position 311), G265D (an amino acid changed from glycine to aspartic at position 265), N609T (an amino acid changed from asparagine to threonine at position 609), and G545E (an amino acid changed from glycine to glutamic at position 545), respectively. The mutants $\mathrm{Sg}-17$ and $\mathrm{Sg}-28$ had the same mutations, Q369P (an amino acid changed from glutamine to proline at position 369) and N373S (an amino acid changed from asparagine to serine at position 373). In addition, the mutant Sg-17 carried five other point mutations, including R319K (an amino acid changed from arginine to lysine at position 319), V336M (an amino acid changed from valine to methionine at position 336), D337 N (an amino acid changed from aspartic to asparagine at position 337), V346I (an amino acid changed from valine to isoleucine at position 346), and A350S (an amino acid changed from alanine to serine at position 350 ). The $\mathrm{Sg}-38$ mutant carried an additional point mutation, G262S (an amino acid changed from glycine to serine at position 262). Most of these mutations were distributed in the six HAMP domains of the N-terminal region, except for the two laboratory resistant mutants $(\mathrm{Nj5}-10 \mathrm{R}$ and Bt6-4R1) with the mutations located in HATPase_c of the C-terminal region (Table 5).

Expression of Bchog1 in the resistant mutants and sensitive strains. In the absence of fludioxonil, the expression of $\mathrm{BcHog} 1$ did not differ between the sensitive and resistant mutants $(P>0.05)$. When treated

Table 5. Mutation in Bosl protein sequence in laboratory and field resistant mutants of Botrytis cinerea

\begin{tabular}{|c|c|c|c|}
\hline Isolates or mutants & Origin $^{x}$ & Bos1 protein sequence ${ }^{y}$ & Structural domain $^{z}$ \\
\hline Nj5-10 & Field, S & WT & $\ldots$ \\
\hline Bt3-4 & Field, S & WT & $\ldots$ \\
\hline Bt6-4 & Field, $\mathrm{S}$ & WT & $\ldots$ \\
\hline Yc-6 & Field, S & WT & $\ldots$ \\
\hline $\mathrm{Sg}-2$ & Field, S & WT & $\ldots$ \\
\hline $\mathrm{Sg}-28$ & Field, $\mathrm{S}$ & WT & $\ldots$ \\
\hline Wf-20 & Field, S & WT & $\ldots$ \\
\hline Wf-142 & Field, S & WT & $\ldots$ \\
\hline Bt6-4R2 & Laboratory, LR & No mutation & $\ldots$ \\
\hline Yc-6R2 & Laboratory, LR & No mutation & $\ldots$ \\
\hline Nj5-10R & Laboratory, HR & Q846STOP & HATPase_c \\
\hline $\mathrm{Bt} 3-4 \mathrm{R}$ & Laboratory, HR & E253D & Between HAMP2 and HAMP3 \\
\hline Bt6-4R1 & Laboratory, HR & $\begin{array}{l}\text { 55-bp duplication at amino acid position } 835 \\
\text { and resulting in } 838 \mathrm{STOP}\end{array}$ & HATPase_c \\
\hline Yc-6R1 & Laboratory, HR & G415D & HAMP3 \\
\hline Sg-17 & Field, HR & $\begin{array}{l}\text { R319K, V336M, D337 N, V346I, A350S, } \\
\text { Q369P, N373S }\end{array}$ & HAMP2, HAMP3, and between them \\
\hline $\mathrm{Sg}-38$ & Field, HR & G262S, Q369P, N373S & HAMP1, between HAMP2 and HAMP3 \\
\hline Wf-55 & Field, HR & G311R & HAMP2 \\
\hline Wf-161 & Field, HR & G265D & Between HAMP 1 and HAMP 2 \\
\hline Wf-192 & Field, HR & N609T & HAMP5 \\
\hline Wf-202 & Field, HR & G545E & Between HAMP4 and HAMP5 \\
\hline
\end{tabular}

${ }^{x}$ Field, $\mathrm{S}=$ field sensitive isolates; Laboratory, HR or LR = highly resistant mutants or mutants with low resistance, respectively, which were obtained by selection on fludioxonil-amended medium in the laboratory; and Field, HR = HR mutants which were collected from the field locations.

y WT = wild type.

${ }^{\mathrm{z}}$ HATPase_c = histidine kinase-, DNA gyrase B-, and HSP90-like ATPase. HAMP = histidine kinases, adenylate cyclases, methyl-accepting chemotaxis proteins, and some phosphatases; in the case of the B. cinerea Bos1, there are six repeats of HAMP domains. 
with fludioxonil at $1 \mu \mathrm{g} / \mathrm{ml}$, the expression of $\mathrm{BcHog} 1$ was upregulated in all the sensitive strains and resistant mutants but the expression levels of $B c H o g l$ in the resistant mutants were significantly lower than those in the sensitive strains (Fig. 4). A negative correlation between the levels of resistance to fludioxonil and the expression of BcHogl was observed under pressure of fludioxonil (Fig. 4). These results indicated that the resistant mutants had a weaker capacity to activate the HOG MAPK pathway when stressed by fludioxonil.

\section{Discussion}

Fludioxonil can strongly inhibit mycelial growth and spore germination of B. cinerea (Zhao et al. 2010), and was registered in 2012 in China to control gray mold. However, populations from strawberry and blackberry with low fludioxonil resistance from the United States developed in 2014 (Fernández-Ortuño et al. 2014a, b; Li et al. 2014). Although it is at the early stage of introduction for controlling gray mold in China, we care about whether the fludioxonilresistant populations develop in the field. Therefore, fludioxonilsensitivity shifts of B. cinerea isolates were detected during 2012 to 2014 in the regions of Jiangsu and Shandong Provinces in China that had a history of fludioxonil application. Our data showed that fludioxonil-resistant populations were not detected in Jiangsu Province but fludioxonil-resistant populations developed in two cities, Shouguang $(\mathrm{LR} / \mathrm{HR}$ frequency $=10.67 / 2.67 \%)$ and Weifang (LR/HR frequency $=17.21 / 1.30 \%$ ), of Shandong Province. It remains to be determined whether HR frequency will increase if the fludioxonil-containing Celest continues to be used in these fields.

Six resistant mutants were generated in the laboratory by fungicide training and the resistance of these mutants against fludioxonil was stable through 10 transfers on fungicide-free PDA plates. All of the HR field and laboratory resistant isolates exhibited reduced mycelial growth, sporulation, and virulence, which indicated that resistance to fludioxonil imposes a fitness cost relative to isolates that lack this resistance. Similar results were reported for fludioxonil-resistant mutants in Penicillium expansum (Li and Xiao 2008) and Sclerotinia sclerotiorum (Kuang et al. 2011). Based on our results and previous studies about resistance risk assessment (Wu et al. 2014), resistance risk of $B$. cinerea to fludioxonil should be classified as moderate and resistance management should be considered. These include good crop management and sanitation to reduce the risk of gray mold infection, such as limitation of nitrogen fertilizer, reduction of the humidity, and removal of infected fruit and plant parts. To limit selection for resistance, rotation between fungicides of different classes and limitation of treatments with the same class of compounds to one per season should be mandatory. Additionally, as expected, positive cross-resistance was observed between fludioxonil and dicarboximides (e.g., procymidone and iprodione) in the field and laboratory isolates tested. Therefore, growers should limit use of fludioxonil or apply it in mixture with other fungicides which have different modes of action.

Two-component systems are composed of a His-Asp phosphorelay from the HK to the response regulator (Bahn 2008). The fungicide fludioxonil affects the fungal osmotic signal transduction cascade (Bahn et al. 2006). It is used to control phytopathogenic fungi by causing improper activation of the HOG1-type MAPK (Furukawa et al. 2012; Kojima et al. 2004). In previous studies, the field and laboratory resistant mutants showed increased sensitivity to osmotic stress.

In our study, the field HR mutants showed hypersensitivity to osmotic stress, mutation in Bosl, and abnormal expression of Bchogl. We speculated that fludioxonil resistance resulted from suppressing the activation of the HOG-MAPK pathway under fludioxonil or osmotic stresses.

Osmosensing HK of filamentous fungi belong principally to group III HK (Liu et al. 2008). These HK are involved in adaptation to adverse environmental conditions such as osmotic and fungicide stresses. Group III also plays essential role in the development and

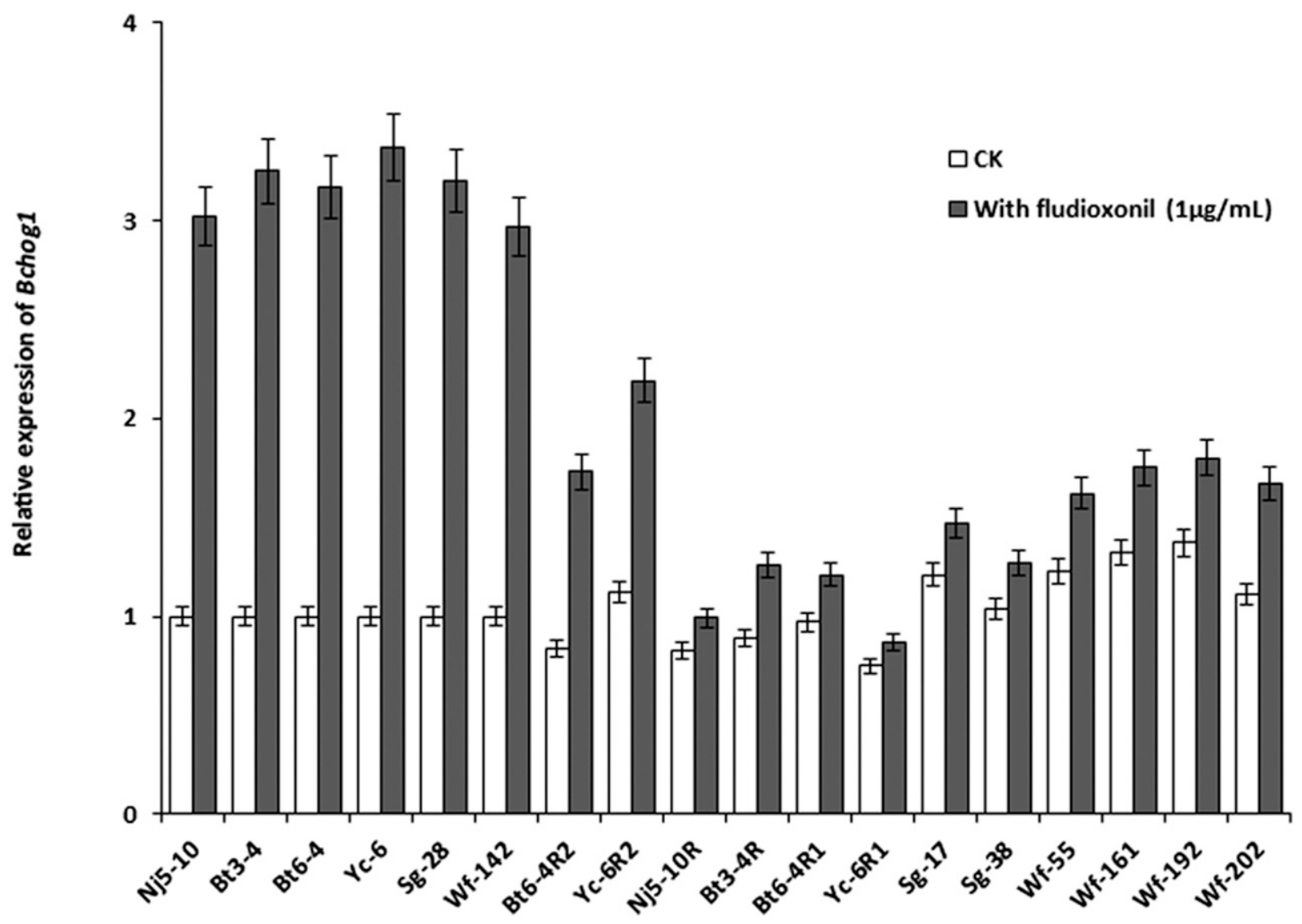

Fig. 4. Expression of Bchog1 in the resistant mutants and sensitive isolates of Botrytis cinerea. Mycelia of each isolate or mutant were treated with fludioxonil at $1 \mu \mathrm{g} / \mathrm{ml}$ after growth in potato dextrose broth for 3 days. Cultures without treatment were used as the controls (CK). Bars denote standard errors from three repeated experiments. 
pathogenesis of fungi. This may explain why strains HR to fludioxonil are hardly found under field conditions. In this study, when treated with fludioxonil at $1 \mu \mathrm{g} / \mathrm{ml}$, glycerol concentrations and expression levels of Bchogl in the sensitive strains increased significantly, whereas those in field and laboratory resistant mutants did not. These results indicated that the resistant mutants had a weaker capacity to activate the HOG-MAPK pathway under fludioxonil pressure and suggested a negative correlation between the levels of resistance to fludioxonil and the increments of glycerol accumulation under pressure of fludioxonil.

Group III HK function as responsible upstream factors to regulate the HOG1-type MAPK (Catlett et al. 2003) and are involved in glycerol synthesis (Hohmann 2002). Thus, in the present study, Bosl genes (which encode the group III HK in B. cinerea) of the field and laboratory resistant mutants were cloned and analyzed. All mutations in the field HR mutants were located in the HAMP domains of the N-terminal region of OS1. Mutations in the laboratory HR mutants, however, were classified into two types: mutations located in HAMP domains (type I) and mutations located in the HATPase_c domain of the C-terminal region (type II). Under laboratory circumstances, a series of gradient concentrations $(0.1,5$, and $50 \mu \mathrm{g} / \mathrm{ml})$ of fludioxonil were used to generate resistant mutants in the current study, and the mutations harbored at the domains of HAMP or HATPase_c of OS1 in the laboratory mutants. However, fludioxonil at about $50 \mu \mathrm{g} / \mathrm{ml}$ is recommended to control gray mold in the field, where the fludioxonil selection pattern was totally different from that under laboratory conditions, mainly due to the influence of environmental factors, and all mutations were confined at the domains of HAMP. This is the first report of the type II mutation conferring fludioxonil resistance. Our research contradicts previous opinions that only mutations located in HAMP domains of group III HK confer fludioxonil resistance, and the resistance mechanism in both laboratory and field mutants is currently under further investigation in our laboratory.

\section{Acknowledgments}

This research was supported by: the Special Fund for Agro-scientific Research in the Public Interest (numbers 201303025 and 201303023), a grant from the National Natural Science Foundation of China (number 31171880), and a grant from Jiangsu Province Agricultural Independent Innovation Foundation (number CX[14]2054).

\section{Literature Cited}

Bahn, Y.-S. 2008. Master and commander in fungal pathogens: The twocomponent system and the HOG signaling pathway. Eukaryot. Cell 7: 2017-2036.

Bahn, Y.-S., Kojima, K., Cox, G. M., and Heitman, J. 2006. A unique fungal twocomponent system regulates stress responses, drug sensitivity, sexual development, and virulence of Cryptococcus neoformans. Mol. Biol. Cell 17:3122-3135.

Catlett, N. L., Yoder, O. C., and Turgeon, B. G. 2003. Whole-genome analysis of two-component signal transduction genes in fungal pathogens. Eukaryot. Cell 2:1151-1161.

Duan, Y., Ge, C., Liu, S., Wang, J., and Zhou, M. 2013. A two-component histidine kinase Shk1 controls stress response, sclerotial formation and fungicide resistance in Sclerotinia sclerotiorum. Mol. Plant Pathol. 14: $708-718$.

Duan, Y.-B., Ge, C.-Y., and Zhou, M.-G. 2014. Molecular and biochemical characterization of Sclerotinia sclerotiorum laboratory mutants resistant to dicarboximide and phenylpyrrole fungicides. J. Pest Sci. 87:221-230.

Elad, Y. 1997. Responses of plants to infection by Botrytis cinerea and novel means involved in reducing their susceptibility to infection. Biol. Rev. 72:381-422.

Elad, Y., Yunis, H., and Katan, T. 1992. Multiple fungicide resistance to benzimidazoles, dicarboximides and diethofencarb in field isolates of Botrytis cinerea in Israel. Plant Pathol. 41:41-46.

Fernández-Ortuño, D., Grabke, A., Bryson, P. K., Beasley, E. D., Fall, L. A., Brannen, P. M., and Schnabel, G. 2014a. First report of fludioxonil resistance in Botrytis cinerea from a blackberry field in Georgia. Plant Dis. 98:848.

Fernández-Ortuño, D., Grabke, A., Bryson, P. K., Rouse, R. J., Rollins, P., and Schnabel, G. 2014b. First report of fludioxonil resistance in Botrytis cinerea, the causal agent of gray mold, from strawberry fields in Maryland and South Carolina. Plant Dis. 98:692.

Fillinger, S., Ajouz, S., Nicot, P. C., Leroux, P., and Bardin, M. 2012. Functional and structural comparison of pyrrolnitrin- and iprodione-induced modifications in the class III histidine-kinase Bosl of Botrytis cinerea. PLoS One 7:e42520.
Furukawa, K., Randhawa, A., Kaur, H., Mondal, A. K., and Hohmann, S. 2012. Fungal fludioxonil sensitivity is diminished by a constitutively active form of the group III histidine kinase. FEBS Lett. 586:2417-2422.

Furukawa, K., Yoshimi, A., Furukawa, T., Hoshi, Y., Hagiwara, D., Sato, N., Fujioka, T., Mizutani, O., Mizuno, T., Kobayashi, T., and Abe, K. 2007. Novel reporter gene expression systems for monitoring activation of the Aspergillus nidulans HOG pathway. Biosci. Biotechnol. Biochem. 71:1724-1730.

Gehmann, K., Nyfeler, R., Leadbeater, A. J., Nevill, D. J., and Sozzi, D. 1990 CGA 173506: A new phenylpyrrole fungicide for broad-spectrum disease control. Pages 399-406 in: Brighton Crop Prot. Conf. Pests Dis.

Hagiwara, D., Matsubayashi, Y., Marui, J., Furukawa, K., Yamashino, T., Kanamaru, K., Kato, M., Abe, K., Kobayashi, T., and Mizuno, T. 2007. Characterization of the NikA histidine kinase implicated in the phosphorelay signal transduction of Aspergillus nidulans, with special reference to fungicide responses. Biosci. Biotechnol. Biochem. 71:844-847.

Hohmann, S. 2002. Osmotic stress signaling and osmoadaptation in yeasts Microbiol. Mol. Biol. Rev. 66:300-372.

Kojima, K., Takano, Y., Yoshimi, A., Tanaka, C., Kikuchi, T., and Okuno, T. 2004. Fungicide activity through activation of a fungal signalling pathway. Mol. Microbiol. 53:1785-1796.

Kuang, J., Hou, Y.-P., Wang, J.-X., and Zhou, M.-G. 2011. Sensitivity of Sclerotinia sclerotiorum to fludioxonil: In vitro determination of baseline sensitivity and resistance risk. Crop Prot. 30:876-882.

Leroch, M., Kretschmer, M., and Hahn, M. 2011. Fungicide resistance phenotypes of Botrytis cinerea isolates from commercial vineyards in south west Germany. J. Phytopathol. 159:63-65.

Leroux, P. 1996. Recent developments in the mode of action of fungicides. Pestic. Sci. 47:191-197.

Leroux, P. 2007. Chemical control of Botrytis and its resistance to chemical fungicides. Pages 195-222 in: Botrytis: Biology, Pathology and Control. Y. Elad, B. Williamson, P. Tudzynski, and N. Delen, eds. Kluwer Academic Publishers, Dordrecht, The Netherlands.

Leroux, P., Fritz, R., Debieu, D., Albertini, C., Lanen, C., Bach, J., Gredt, M., and Chapeland, F. 2002. Mechanisms of resistance to fungicides in field strains of Botrytis cinerea. Pest Manage. Sci. 58:876-888.

Li, H. X., and Xiao, C. L. 2008. Characterization of fludioxonil-resistant and pyrimethanil-resistant phenotypes of Penicillium expansum from apple. Phytopathology 98:427-435.

Li, X., Fernández-Ortuño, D., Grabke, A., and Schnabel, G. 2014. Resistance to fludioxonil in Botrytis cinerea isolates from blackberry and strawberry. Phytopathology 104:724-732.

Liu, W., Leroux, P., and Fillinger, S. 2008. The HOG1-like MAP kinase Sak1 of Botrytis cinerea is negatively regulated by the upstream histidine kinase Bos 1 and is not involved in dicarboximide- and phenylpyrrole-resistance. Fungal Genet. Biol. 45:1062-1074.

Mascher, T., Helmann, J. D., and Unden, G. 2006. Stimulus perception in bacterial signal-transducing histidine kinases. Microbiol. Mol. Biol. Rev. 70:910-938.

Meena, N., Kaur, H., and Mondal, A. K. 2010. Interactions among HAMP domain repeats act as an osmosensing molecular switch in group III hybrid histidine kinases from fungi. J. Biol. Chem. 285:12121-12132.

Motoyama, T., Ohira, T., Kadokura, K., Ichiishi, A., Fujimura, M., Yamaguchi, I., and Kudo, T. 2005. An Os-1 family histidine kinase from a filamentous fungus confers fungicide-sensitivity to yeast. Curr. Genet. 47:298-306.

Myresiotis, C. K., Karaoglanidis, G. S., and Tzavella-Klonari, K. 2007. Resistance of Botrytis cinerea isolates from vegetable crops to anilinopyrimidine phenylpyrrole, hydroxyanilide, benzimidazole, and dicarboximide fungicides. Plant Dis. 91:407-413.

Nishida, M., Matsubara, T., and Watanabe, N. 1965. Pyrrolnitrin, a new antifungal antibiotic. Microbiological and toxicological observations. J. Antibiot. 18: 211-219.

Ochiai, N., Fujimura, M., Motoyama, T., Ichiishi, A., Usami, R., Horikoshi, K., and Yamaguchi, I. 2001. Characterization of mutations in the two-component histidine kinase gene that confer fludioxonil resistance and osmotic sensitivity in the os-1 mutants of Neurospora crassa. Pest Manage. Sci. 57:437-442.

Ochiai, N., Fujimura, M., Oshima, M., Motoyama, T., Ichiishi, A., YamadaOkabe, H., and Yamaguchi, I. 2002. Effects of iprodione and fludioxonil on glycerol synthesis and hyphal development in Candida albicans. Biosci. Biotechnol. Biochem. 66:2209-2215.

Raaijmakers, J., Vlami, M., and de Souza, J. 2002. Antibiotic production by bacterial biocontrol agents. Antonie Leeuwenhoek 81:537-547.

Ristaino, J. B., Madritch, M., Trout, C. L., and Parra, G. 1998. PCR amplification of ribosomal DNA for species identification in the plant pathogen genus Phytophthora. Appl. Environ. Microbiol. 64:948-954.

Stock, A. M., Robinson, V. L., and Goudreau, P. N. 2000. Two-component signal transduction. Annu. Rev. Biochem. 69:183-215.

Vignutelli, A., Hilber-Bodmer, M., and Hilber, U. W. 2002. Genetic analysis of resistance to the phenylpyrrole fludioxonil and the dicarboximide vinclozolin in Botryotinia fuckeliana (Botrytis cinerea). Mycol. Res. 106:329-335.

Wang, Y., Duan, Y. B., and Zhou, M. G. 2015. Molecular and biochemical characterization of boscalid resistance in laboratory mutants of Sclerotinia sclerotiorum. Plant Pathol. 64:101-108.

Williamson, B., Tudzynski, B., Tudzynski, P., and Van Kan, J. A. L. 2007. Botrytis cinerea: The cause of grey mould disease. Mol. Plant Pathol. 8:561-580. 
Wu, D.-X., Zhang, X.-K., Ji, W., Wang, J.-X., Zhou, M.-G., and Chen, C.-J. 2014. Baseline sensitivity of Botrytis cinerea and risk assessment of developing resistance to the novel fungicide Y5247. Australas. Plant Pathol. 43:639-651.

Yoshimi, A., Kojima, K., Takano, Y., and Tanaka, C. 2005. Group III histidine kinase is a positive regulator of Hog1-type mitogen-activated protein kinase in filamentous fungi. Eukaryot. Cell 4:1820-1828.

Yoshimi, A., Tsuda, M., and Tanaka, C. 2004. Cloning and characterization of the histidine kinase gene Dic1 from Cochliobolus heterostrophus that confers dicarboximide resistance and osmotic adaptation. Mol. Genet. Genomics 271:228-236.
Zhang, Y., Lamm, R., Pillonel, C., Lam, S., and Xu, J.-R. 2002. Osmoregulation and fungicide resistance: The Neurospora crassa os-2 gene encodes a HOG1 mitogenactivated protein kinase homologue. Appl. Environ. Microbiol. 68:532-538.

Zhao, H., Kim, Y. K., Huang, L., and Xiao, C. L. 2010. Resistance to thiabendazole and baseline sensitivity to fludioxonil and pyrimethanil in Botrytis cinerea populations from apple and pear in Washington State. Postharvest Biol. Technol. 56:12-18.

Ziogas, B. N., and Kalamarakis, A. E. 2001. Phenylpyrrole fungicides: Mitotic instability in Aspergillus nidulans and resistance in Botrytis cinerea. J. Phytopathol. 149:301-308. 